\title{
Anterior mediastinotomy
}

\author{
D. S. EVANS, J.H. HALL, and G. KENT HARRISON \\ Department of Cardiothoracic Surgery, St. Thomas' Hospital, London S.E.I
}

\begin{abstract}
The indications and techniques for performing the operation of anterior mediastinotomy are described. In the years 1966-71, 116 anterior mediastinotomies were done. The results of these are presented.

In 36 patients the operation was done to provide a histological diagnosis in benign conditions. In 51 patients, with probable carcinoma but normal bronchoscopy, mediastinotomy was done to establish a diagnosis and assess operability; 43 had involved mediastinal nodes proven on histology. In a further 29 patients, with positive bronchoscopic biopsies, mediastinotomy was done to assess operability alone. In all, 14 patients (17.5\%) were judged suitable for thoracotomy. Of these, nine had operable disease while five were found to be inoperable.

The incidence of complications of the operation was low (11\%). These were mostly minor, There were no deaths. Most patients, after anterior mediastinotomy alone, were fit for discharge 48 to 72 hours after the operation.

The value of an operation that provides both diagnosis and assessment of mediastinum, lung, and pleura is discussed. The operation of anterior mediastinotomy is compared with mediastinoscopy and, in our opinion, the superiority of the former is demonstrated.
\end{abstract}

In this unit the presence of malignant nodes in the mediastinum is a contraindication to radical surgery for carcinoma of the lung. The place of anterior mediastinotomy to obtain this information and to make diagnoses in obscure lung, pleural, and mediastinal pathology is discussed. It is not proposed to enter the arguments for or against radical or supraradical surgery but rather, with the above criteria in mind, to assess the merits of a minor diagnostic procedure for the prevention of unnecessary thoracotomy with its associated morbidity and discomfort for the patient.

In the presence of diagnosed carcinoma of the bronchus, with suspect mediastinal involvement on chest radiography, patients were selected for anterior mediastinotomy only if their general condition and/or bronchoscopic appearance were favourable for lung resection. Eighty-one patients, in the review period, underwent lung resection without mediastinotomy as they had no suggestion of mediastinal involvement on the chest film. Where there was doubt as to the diagnosis mediastinotomy was performed for diagnosis and for assessment for thoracotomy.

Carlens (1959) described the technique of mediastinoscopy in an attempt to diagnose the presence of lymph node metastases in carcinoma of the bronchus. It was a logical extension of the scalene node biopsy, as sezondary involvement of the paratracheal lymph nodes could be determined. In 1965 Chamberlain and Stemner, Calvin, Chander, and Connolly described the technique of anterior mediastinotomy. The latter demanded that four criteria should be fulfilled:

(1) In the majority of cases it should be able to provide a histological diagnosis where none was available.

(2) It should detect the presence of unresectable disease.

(3) It should establish whether the operation required to eliminate the local disease would be tolerated by the patient.

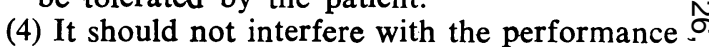
of a formal subsequent thoracotomy.

This paper presents our experience of anterior N mediastinotomy in 116 patients in the years 196671 and confirms that it fulfils these criteria.

\section{TECHNIQUE}

Under general anaesthesia with endotracheal intuba- $\frac{T}{0}$ tion a vertical incision is made $1 \mathrm{~cm}$ lateral to the $\frac{\vec{D}}{\mathbb{D}}$ sternal edge and anterior to the second and third $\stackrel{\rho}{\mathscr{P}}$

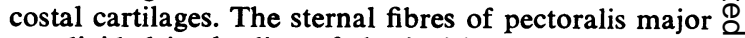
are divided in the line of the incision, and 3 to $4 \mathrm{~cm}$ lengths of the second and third costal cartilages are excised subperichondrally and discarded. The internal 
mammary vessels are divided at the upper end of the wound, and the pleura is separated from the under surface of the sternum and the mediastinum by finger dissection.

By a mixture of blunt and sharp dissection the structures of the mediastinum and hilar region are exposed to a varying degree. On the right side the thymus gland, ascending aorta, superior vena cava, phrenic nerve, superior pulmonary vein, pulmonary artery branches, and main bronchus may be seen or palpated. On the left side the following structures may be evident: the thymus gland, the ascending aorta, branches of the pulmonary artery and superior pulmonary vein, the main bronchus, and the phrenic nerve.

Abnormal tissues in the mediastinum can be readily seen and or palpated but, because of the close proximity of major vessels, it is often advisable to aspirate with syringe and needle before taking a biopsy. The pleural cavity can be entered and both pleural and lung biopsies taken. The wound is closed in a routine manner with a $3 \mathrm{~mm}$ underwater seal drain to the mediastinum or pleural cavity as indicated. This is removed usually after 24 hours and the patient is allowed home after 48 to 72 holurs if no further surgery is contemplated.

\section{RESULTS}

In the six years 1966-71 inclusive, 116 anterior mediastinotomies have been performed. The operation was indicated for two main reasons: to establish the diagnosis of mediastinal and lung conditions, either benign or malignant, and to determine whether mediastinal nodes were involved in cases of carcinoma of the bronchus.

Table I shows the results of mediastinotomy for the diagnosis of conditions other than carcinoma of the bronchus. Sarcoidosis and interstitial fibrosis were the most common diagnoses. The 'others' group inc.uded a haematoma and chronic inflammatory tissue from a lung abscess. In five cases the apparent mass seen on the chest radiograph

T A B LE I

RESULTS OF MEDIASTINOTOMY FOR CONDITIONS OTHER THAN CARCINOMA OF BRONCHUS

\begin{tabular}{l|c|c|c|c}
\hline \multicolumn{1}{c|}{ Findings } & $\begin{array}{c}\text { No. } \\
\text { of } \\
\text { Cases }\end{array}$ & \multicolumn{3}{|c|}{ Site of Biopsy } \\
\cline { 3 - 5 } & Mediastinum & Pleura & Lung \\
\hline Sarcoidosis & 7 & 7 & - & 1 \\
$\begin{array}{l}\text { Interstitial fibrosis } \\
\text { Tuberculosis }\end{array}$ & 7 & 1 & 2 & 7 \\
$\begin{array}{l}\text { Reticuloses } \\
\text { Thymic tumour }\end{array}$ & 5 & 5 & 1 & 1 \\
$\begin{array}{l}\text { Secondary malignant } \\
\text { disease }\end{array}$ & 2 & 2 & - & - \\
$\begin{array}{l}\text { Others } \\
\text { Mass on chest film } \\
\text { not demonstrated }\end{array}$ & 2 & 2 & - & - \\
\hline \multicolumn{1}{c|}{ Total } & 5 & 3 & 1 & 1 \\
\hline
\end{tabular}

${ }^{1}$ This includes biopsies from different sites in the same patient. was not demonstrated at mediastinotomy. The site of the biopsy is shown in columns 2 to 4 . Frequently biopsies were taken from more than one site.

\section{T A B L E I I}

RESULTS OF MEDIASTINOTOMY IN THE DIAGNOSIS OF CARCINOMA OF THE BRONCHUS-NORMAL BRONCHOSCOPY

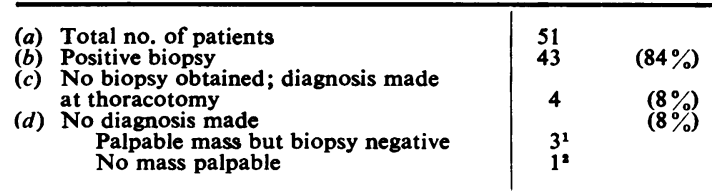

${ }^{1}$ Consisted of one specimen in which the mass was not biopsied, that is, the wrong tissue, and two specimens in which the fragments were too small for identification.

'Patient died one month later; carcinoma of the bronchus was shown at necropsy.

Table II shows the results of mediastinotomy for the diagnosis of carcinoma of the bronchus, when bronchoscopy and sputum cytology showed no abnormality. Of 51 patients, 43 had palpable nodes and a positive biopsy was obtained. In four patients neither mediastinal nodes nor a mass in the lung substance could be palpated and the diagnosis was subsequently made at thoracotomy. In a further four patients no firm diagnosis was made; three had a palpable mass, and were diagnosed clinically as carcinoma, but the biopsy failed to confirm the diagnosis. In one, the proximity of the great vessels prevented an accurate biopsy, histology showing normal structures only. In two, the fragments, obtained by aspiration, were too small to be identified, while in the fourth patient no mass was palpable.

\section{T A B L E I I I}

RESULTS OF MEDIASTINOTOMY AS ASSESSMENT FOR OPERABILITY/THORACOTOMY FOR CARCINOMA OF

\begin{tabular}{|c|c|c|c|c|c|c|c|}
\hline \multirow{2}{*}{$\frac{\text { Category }}{\text { Positive biopsy }} \begin{array}{l}\text { at bronchoscopy } \\
\text { a }\end{array}$} & \multirow{2}{*}{$\frac{\text { Total }}{29}$} & \multicolumn{2}{|c|}{$\begin{array}{l}\text { Proceed to } \\
\text { Thoracotomy }\end{array}$} & \multicolumn{2}{|c|}{ Operable } & \multicolumn{2}{|c|}{ Inoperable } \\
\hline & & 10 & $(12 \cdot 5 \%)$ & 6 & $(7 \cdot 5 \%)$ & 4 & $(5 \%)$ \\
\hline $\begin{array}{l}\text { Positive biopsy at } \\
\text { mediastinotomy; } \\
\text { bronchial biopsy } \\
\text { negative }\end{array}$ & 43 & 0 & & 0 & & 0 & \\
\hline $\begin{array}{l}\text { No biopsy } \\
\text { obtained at } \\
\text { mediastinotomy }\end{array}$ & 4 & 4 & $(5 \%)$ & 3 & $(4 \%)$ & $1^{1}$ & $(1 \cdot 25 \%)$ \\
\hline $\begin{array}{l}\text { Negative } \\
\text { biopsy at } \\
\text { mediastinotomy }\end{array}$ & 4 & 0 & & 0 & & 0 & \\
\hline All categories & 80 & 14 & $(17 \cdot 5 \%)$ & & $(11.5 \%)$ & 5 & $(6 \cdot 25 \%)$ \\
\hline
\end{tabular}

${ }^{1}$ Adherent to the chest wall.

'See $(d)$ in Table II. 
Table III presents the results of mediastinotomy as a guideline for the performance of a thoracotomy. A thoracotomy was not performed if there were involved mediastinal nodes or other local factors such as mediastinal or chest wall infiltration. Of 80 patients assessed, only 29 had a positive biopsy on bronchoscopy. In 10 of these thoracotomy was indicated and at operation six proved to be operable. In the four cases which were found to be inoperable, growth had infiltrated the mediastinum posterior to the pulmonary artery and vein. In the 51 patients normal on bronchoscopy, 43 had involvement of the mediastinal structures and a positive biopsy. In these a thoracotomy was not performed. Of the remaining eight patients, four had no palpable mass at mediastinotomy. At thoracotomy a resection was performed in three; the fourth was inoperable because of adherence to the chest wall. Finally, the four patients in Table II $(d)$ did not proceed to thoracotomy for other medical reasons. The clinical diagnosis was subsequently proved to be correct in all.

The morbidity of the operation has been minimal (Table IV). In four patients there was a wound infection, as evidenced by formation of pus, and two further patients had wound haematomas which required evacuation. In three patients there was a postoperative chest infection, probably a complication of the anaesthetic, and in a further three a small pleural effusion developed, which may have been caused by the operation or by the underlying disease. One patient complained of severe pain in his wound for which no explanation was found. The scars have generally healed well, except for one depressed scar in a young woman with Hodgkin's disease of the sternum. There were no deaths attributable to the operation.

T A B LE I V

MORBIDITY OF MEDIASTINOTOMY

\begin{tabular}{l|cc}
\hline & No. & $\%$ \\
\hline Wound infection & 4 & $3 \cdot 4$ \\
Postoperative bronchopneumonia & 3 & $2 \cdot 6$ \\
Pleural effusion & 3 & $2 \cdot 6$ \\
Wound haematoma & 2 & $1 \cdot 7$ \\
Wound pain (severe) & 1 & $0 \cdot 9$ \\
\hline
\end{tabular}

\section{DISCUSSION}

The anatomical pathways which the pulmonary lymph flow follows were originally shown by Rouviere (1932) to be the hilar, subcarinal, para- tracheal, and, finally, the supraclavicular nodes The technique of scalene node biopsy, as ad=o vocated by Daniels (1949), has been widely prac-을 tised in this country but will give information only in cases where the disease has spread beyond the limits of the thoracic cavity. A technique that willow assess or provide biopsy material in an intrathoracic lesion is obviously of great value in the early diagnosis and subsequent management of $\vec{\omega}$ the disease. Anterior mediastinotomy is such ao procedure; it may provide material for histology which is not available on bronchoscopy or it mayi detect a surgically incurable lesion and so avoid the hazard of a thoracotomy. The indications for diagnostic anterior mediastinotomy were well $+\overrightarrow{+}$ documented by McNeill and Chamberlain (1966).윽 Calvin et al. (1971) reported further use of the pro-cedure in minor operations on the heart, including $\subseteq$ implantation of pacemakers, pericardial and myo cardial biopsy, and pericardial drainage.

The operation is simple to perform and can be done under local anaesthetic, though we have not found this to be necessary in any of our patients. Most of the structures in the anterior mediastinums can be inspected and palpated through an appro-priate incision. The pleura can be opened and inspected and the lung substance palpated and $\odot$ biopsied. However (because of the proximity of $\overrightarrow{\vec{O}}$ the major blood vessels), care is needed in the 3 biopsy of suspicious tissues in the mediastinum. It is recommended that aspiration with a long. needle should be attempted before a biopsy is taken. Despite this there have been two severe응 venous haemorrhages. These were controlled by pressure and suture through the mediastinotomyo incision without resort to thoracotomy. Haemorr hage from the internal mammary artery and veino is occasionally a problem. This can be controlled ${ }^{2}$ by compression of the vessels against the first and second costal cartilages. We have always inserted a soft rubber catheter attached to an underwatero. seal both for drainage of blood and as a precaution against the development of a pneumothorax. Where mediastinotomy was negative, we have 0 usually turned the patient and proceeded immediately to thoracotomy.

The morbidity of the operation has been lowe and we have had no operative deaths. This com- $-\frac{1}{\mathbb{N}}$ pares favourably with mediastinoscopy in most? series. Comparison between the two operations is inevitable. Anterior mediastinotomy would seem $\overline{\vec{O}}$ to us to have the following advantages. First, in addition to the anterior mediastinum, the peri-庹 cardium and myocardium can be reached through an appropriate incision. The pleura can be opened and the lung visualized. Both can be biopsied andô 
pleural fluid aspirated. Secondly, the structures cannot only be seen but also palpated, thus allowing determination of their consistency and fixation. Thirdly, in anterior mediastinotomy, direct access allows better control of any possible complications of biopsy, in particular severe bleeding or the recognition of inadvertent pleural penetration. The main limitation of mediastinotomy in the assessment of operability for cancer is that the degree of any peripheral fixation or infiltration of the tumour on to the chest wall, diaphragm or inferior vena cava may be difficult to determine. The lung may occasionally be unresectable. Compared with a small thoracotomy incision, an anterior mediastinotomy has better access to the mediastinum and causes less disturbance to the patient.

We would like to thank Mr Peter Gornall for help with the collection of the material.

\section{REFERENCES}

Calvin, J. W., Stemmer, E. A., Steedman, R. A., and Connolly, J. E. (1971). Arch. Surg., 102, 322.

Carlens, E. (1959). Mediastinoscopy: a method for inspection and tissue biopsy in the superior mediastinum. Dis. Chest, 36, 343.

Chamberlain, J. M. (1965). Discussion. J. thorac. cardiovasc. Surg., 49, 20.

Daniels, A. C. (1949). Method of biopsy useful in diagnosing certain intrathoracic diseases. Dis. Chest, 16, 360.

McNeill, T. M., and Chamberlain, J. M. (1966). Diagnostic anterior mediastinotomy. Ann. thorac. Surg., 2, 532.

Rouviere, H. (1932). Anatomie des Lymphatiques de l'Homme. Masson et Cie, Paris.

Stemner, E. A., Calvin, J. W., Chandor, S. B., and Connolly, J. E. (1965). Mediastinal biopsy for indeterminate pulmonary and mediastinal lesions. $J$. thorac. cardiovasc. Surg., 49, 405.

Address for reprints:

J. H. Hall, St. Thomas' Hospital, London SE1. 